\title{
Acute Myocardial Infarction From PCl Complication Type
}

National Cancer Institute

\section{Source}

National Cancer Institute. Acute Myocardial Infarction From PCI Complication Type. NCI Thesaurus. Code C119239.

A description of the complications from a percutaneous coronary intervention procedure that lead to an acute myocardial ischemic event. 